\title{
Research on the Results of CET4/6 by Using the Fuzzy Forecast Method
}

\author{
Yalou Liu ${ }^{1, *}$, Miaomiao Jing ${ }^{1}$ and Junyong $\operatorname{Han}^{2}$ \\ ${ }^{1}$ Hebei United University, Tangshan, China $;{ }^{2}$ Beijing International Studies University, Beijing, China
}

\begin{abstract}
As a kind of large-scale standardized test, the College English Test Band Four and Six (CET 4/6) can evaluate the English level of the students through its detailed test content. How to calculate and estimate the relationship between the pass rate of CET 4/6 and the English level of the students has been long concerned by the teaching staff and related teaching administrative personnel. This paper will analyze the grades of CET 4/6 over time and explain the scores, and then utilize the fuzzy theory to do the multiple objective fuzzy assessment and combine the experts' experience, so as to build evaluation mathematical model of pass rate of CET 4/6 and the English level of the students. Through the forecast of the CET 4/6 grades and the analysis of the English skills of the students, this paper can validate the accuracy of the model and analyze the advantages and disadvantages of the CET 4/6.
\end{abstract}

Keywords: CET4/6, forecasting methods, fuzzy theory, proficiency test.

\section{INTRODUCTION}

As a kind of large-scale standardized test, the College English Test Band Four and Six can evaluate the English level of the students through its detailed test content. How to calculate and estimate the relationship between the pass rate of CET 4/6 and the English level of the students has been long concerned by the teaching staff and related teaching administrative personnel. The pass rate of the English level test involves many aspects such as the students' usual standard, different stages assessment examination before the test, pass rate of the same level test for past years, etc. Some of the influence remain vague to the extend that traditional methods can not estimate the results precisely [1].

For CET 4/6, many predecessors had made their own contributions, and thanks to their unremitting efforts, the CET $4 / 6$ grow to be more normative. For example, professor Li youju has made incisive argument on this in 1997 and professor Bachman propound the theory of communicative language competence, in addition, Yang huizhong explanation for scores of CET 4/6. For fuzzy theory research, professor L.A. zadeh, from the Department of Electrical Engineering in the University of California, Berkeley, built the fuzzy set theory and publish a famous paper on the mathematical basis of the theory, in which he promote the fuzzy membership function for the first time and break through the classical mathematics set theory of Kantor in the end of $19^{\text {th }}$ century [2].

On the basis of previous research, this paper will conduct the multiple objective fuzzy assessment by utilizing the fuzzy theory and build evaluation mathematical model of pass rate of CET 4/6 and the English level of the students. Then determine the main factors that affect the English level of college students in line with the model. We are intended to evaluate the pass rate of CET $4 / 6$ and solve the problems of low pass rate and a lack of confidence for the test due to blindly sigh up for the test [3].

\section{EXPLANATION OF CET 4/6 RESULTS}

Along with the growth of international exchange, English, as one of the most common language, is becoming more and more important [4]. Hence all colleges and universities hold CET 4/6 each year with the purpose of making college students pay more attention on English and strengthen the skills practice. But the CET 4/6 is becoming more difficult with the social development, so the scores of the test turns to be the top issue for students [5-7].

After consulting much information, this paper gets the corresponding location of the module scores in CET 4/6 model on the basis of data processing and coordinating. Specific details see Table $\mathbf{1}$.

Table 1. Corresponding location of the module scores in CET $4 / 6$ model.

\begin{tabular}{|c|c|}
\hline $\begin{array}{c}\text { CET-4 Module Scores (Listen- } \\
\text { ing, Reading Comprehension) }\end{array}$ & Percentage (Above) \\
\hline \hline 410 & $10 \%$ \\
\hline 441 & $20 \%$ \\
\hline 453 & $30 \%$ \\
\hline 482 & $40 \%$ \\
\hline 500 & $50 \%$ \\
\hline 518 & $60 \%$ \\
\hline 537 & $70 \%$ \\
\hline 559 & $80 \%$ \\
\hline 590 & $90 \%$ \\
\hline 700 & $100 \%$ \\
\hline
\end{tabular}

2015 Bentham Open 


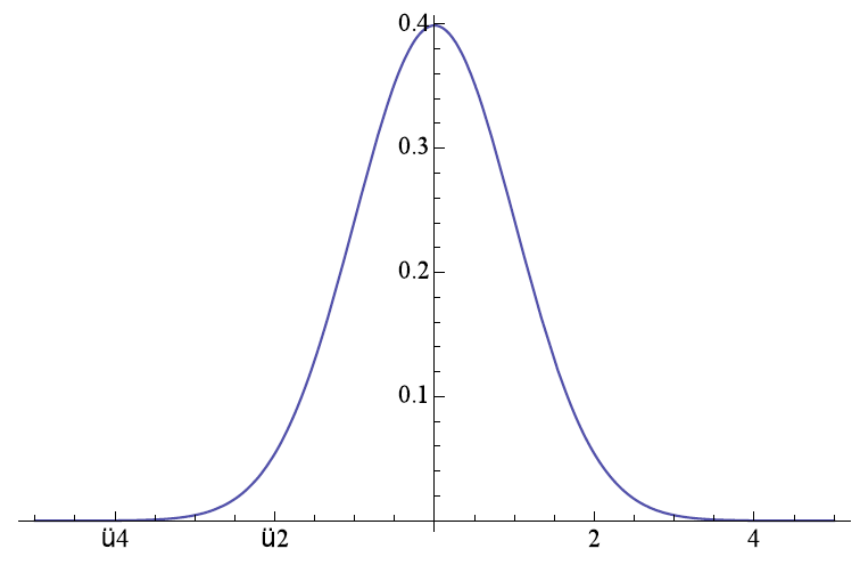

Fig. (1). Trend of CET $4 / 6$ scores graph.

The final scores of the CET 4/6 conform to the normal distribution, see Fig. (1).

\section{MODEL PREPARATION}

\subsection{Fuzzy Theory}

Fuzzy theory utilize the basic concepts of fuzzy set and contact with membership function to solve ubiquitous fuzzy phenomena in real world as well as processing the fuzzy problems which can not be defined by normal methods. Fuzzy information depict the gradual process of transformation from full membership to no membership according to the "membership function. First step is to establish a rough membership function and then to gradually revise and adjust the weight by means of "studying" and experience accumulation. Finally to get a more complete and practical membership function [8].

Fuzzy set can be used to quantitatively describe the fuzzy concepts, it is a bridge between precision and fuzziness. As a generalization of ordinary set, the fuzzy set can be expressed as:

$$
\underline{A}=\frac{\mu_{\underline{A}}\left(\mu_{1}\right)}{U_{1}}+\frac{\mu_{\underline{A}}\left(\mu_{2}\right)}{U_{2}}+\cdots+\frac{\mu_{\underline{A}}\left(\mu_{n}\right)}{U_{n}}=\sum_{i=1}^{n} \frac{\mu A\left(\mu_{i}\right)}{U_{i}}
$$

In which $u_{\underline{A}}\left(u_{i}\right)$ states the membership degree of the $i$-th element $u_{i}$ in the fuzzy set $\underline{A}$; range of membership degree: $0 \leq u_{A}\left(u_{i}\right) \leq 1$. This paper determined to apply Fuzzy mathematics to estimate the pass rate of CET 4/6. Basic evaluating procedures and methods go like this:

1) Establish influencing factors set: $x=\left\{x_{1}, x_{2}\right.$, , $\left.L, x_{i}, L, x_{n}\right\} \quad n=$ objective function

2) Establish weight coefficients set: $G=\left\{g_{1}, g_{2}, L, g_{i}, L\right.$, $\left.g_{n}\right\} \sum_{i=1}^{n} g_{i}=1$

3) Establish evaluation set: $u=\left\{u_{1}, u_{2}, L, u_{i}, u_{m}\right\} \mathrm{m}=$ rating number

4) Establish a fuzzy evaluation matrix contrapose $n$-st assessment objectives:

$$
\mathrm{R}=\left[\begin{array}{l}
\mathrm{R}_{1} \\
R_{2} \\
L \\
R_{I} \\
L \\
R_{n}
\end{array}\right]=\left[\begin{array}{cccccc}
r_{11} & r_{12} & L & r_{1 j} & L & r_{1 m} \\
r_{21} & r_{22} & L & r_{2 j} & L & r_{2 m} \\
L & & & & & \\
r_{i 1} & r_{i 2} & L & r_{i j} & L & r_{i m} \\
L & & & & & \\
r_{n 1} & r_{n 2} & L & r_{n j} & L & r_{n m}
\end{array}\right]
$$

Comprehensive evaluation matrix involves weight coefficient:

$\mathrm{B}=\mathrm{G} \bullet R=\left(g_{1} g_{2} L g_{i} L g_{n}\right)\left[\begin{array}{cccccc}r_{11} & r_{12} & L & r_{1 j} & L & r_{1 m} \\ r_{21} & r_{22} & L & r_{2 j} & L & r_{2 m} \\ L & & & & & \\ r_{i 1} & r_{i 2} & L & r_{i j} & L & r_{i m} \\ L & & & & & \\ r_{n 1} & r_{n 2} & L & r_{n j} & L & r_{n m}\end{array}\right]$

$=\left(b_{1} b_{2} L b_{i} L b_{n}\right)$

$b_{i}$ means $i$-th membership in the comprehensive evaluation set, it adopts the synthetic data model to calculate on the basis of fuzzy matrix. There are two kinds of common computing models.

Model I: $M(\wedge, \vee)$, composite matrix by calculating in line with selecting the $(\wedge)$ first and then the $(\vee)$.

M-model: " $\wedge$ ", " $\vee$ " calculating methods shall confirm to the fowling rules: if $a \wedge b$, then take the small one; if $a \vee b$, then take the large one.

$$
b_{j}=\vee_{i=1}^{n}\left(g_{i} \wedge r_{i j}\right) \quad(j=1,2, L, m)
$$

Model II : $M(g+)$ : calculating principle: first the multiplication and then the addition.

$$
b_{j}=\sum_{i=1}^{n} g_{i} r_{i j} \quad j=1,2, L, m
$$

\subsection{CET 4/6 Pass Rate Evaluation Model}

With the regard to the forecast evaluation of the pass rate of CET $4 / 6$, the actual methods and steps are:

(1) Influencing factors set $X=\left\{x_{1}, x_{2}, x_{3}\right\}=$ \{students' usual standard, assessment examination before the test, pass rate of the same level test for past years\}; in which $\geq 85$ means excellent, 75-85 means good, 60 75 means average, $<60$ means bad.

(2) Weight coefficients $\mathrm{G}=\left\{g_{1}, g_{2}, g_{3}\right\}=\{$ students' usual standard weight, assessment examination before the test weight, pass rate of the same level test for past years weight ; in which students' usual standard weight $=0.2$, assessment examination before the test weight $=0.5$, pass rate of the same level test for past years weight $=0.3$ Table 2 . 
Table 2. Assessment objectives graph of CET 4/6 pass rate.

\begin{tabular}{|c|c|c|c|}
\hline $\begin{array}{c}\text { Student } \\
\text { Objective Evaluation } \\
\text { Objective Assessment }\end{array}$ & 1 & $\mathbf{2}$ & $\mathbf{3}$ \\
\cline { 2 - 4 } & Usual Standard & $\begin{array}{c}\text { Assessment Examination Before } \\
\text { the CET 4/6 }\end{array}$ & $\begin{array}{c}\text { Pass Rate of the Same Level Test } \\
\text { for Past Years }\end{array}$ \\
\hline \hline Student 1 & 86 (excellent) & 82 (good) & $0.85 \sim 0.91$ \\
\hline Student 2 & 74 (average) & 76 (good) & $0.62 \sim 0.67$ \\
\hline Student 3 & 71 (average) & 59 (bad) & $0.41 \sim 0.50$ \\
\hline Student 4 & 79 (good) & 77 (good) & $0.62 \sim 0.67$ \\
\hline
\end{tabular}

(3) Evaluation set $u=\left\{u_{1}, u_{2}, u_{3}, u_{4}\right\}=\{$ high pass rate, normal pass rate, low pass rate, can not pass $\}$; in which $\geq 0.85$ means high pass rate, $>0.75 \sim 0.85$ means normal pass rate, $0.60 \sim 0.75$ means low pass rate, $<0.6$ means can not pass.

(4) Comprehensive evaluation of model

1) Establish a fuzzy evaluation matrix involves N-st assessment objectives

2) Comprehensive evaluation matrix involves weight coefficient

3) Fuzzy comprehensive evaluation value of the pass rate and its corresponding scores in expert database

\subsection{Model Consistency Checks}

Illustrate the research condition of the CET $4 / 6$ pass rate according to the established model.

With expert review, select four students' randomly and the membership matrix of their scores are:

$$
\begin{aligned}
& \mathrm{R}_{1}=\left[\begin{array}{cccc}
0.6 & 0 ! 25 & 0.15 & 0 \\
0.25 & 0.5 & 0.25 & 0 \\
0.25 & 0.5 & 0.25 & 0
\end{array}\right] \\
& R_{\circ}=\left[\begin{array}{cccc}
0 & 0.25 & 0.5 & 0.25 \\
0.25 & 0.5 & 0.25 & 0 \\
0 & 0.25 & 0.5 & 0.25
\end{array}\right] \\
& R_{\circ}=\left[\begin{array}{cccc}
0 & 0.25 & 0.5 & 0.25 \\
0 & 0 & 0.5 & 0.5 \\
0 & 0 & 0.5 & 0.5
\end{array}\right] \\
& R_{\text {o }}=\left[\begin{array}{cccc}
0.25 & 0.5 & 0.25 & 0 \\
0.25 & 0.5 & 0.25 & 0 \\
0 & 0.25 & 0.5 & 0.25
\end{array}\right]
\end{aligned}
$$

Model I obtain the comprehensive evaluation value of each student:

$$
B_{1}=G \bullet R_{1}=(0.2,0.5,0.3) \bullet \mathrm{R}_{1}=\left(b_{1}, b_{2}, b_{3}, b_{4}\right)
$$

Based on the formula (1)

$$
b_{1}=(0.2 \wedge 0.6) \vee(0.5 \wedge 0.25) \vee(0.3 \wedge 0.25)=0.25
$$

Similarly, $\begin{aligned} & b_{2}=0.5 ; b_{3}=0.25 ; b_{4}=0 \\ & B_{\mathrm{II}}=G \bullet \mathrm{R}_{\mathrm{II}}=\left(b_{1}, b_{2}, b_{3}, b_{4}\right)\end{aligned}$

in the same way, $b_{1}=0.25 ; b_{2}=0.5 ; b_{3}=0.3 ; b_{4}=0.25$

$$
B_{\mathrm{III}}=G \bullet \mathrm{R}_{\mathrm{III}}=\left(b_{1}, b_{2}, b_{3}, b_{4}\right)
$$

then $b_{1}=0 ; b_{2}=0.2 ; b_{3}=0.5 ; b_{4}=0.25$

$$
B_{\mathrm{IV}}=G \bullet \mathrm{R}_{\mathrm{IV}}=\left(b_{1}, b_{2}, b_{3}, b_{4}\right)
$$

empathy $b_{1}=0.25 ; b_{2}=0.5 ; b_{3}=0.3 ; b_{4}=0.25$

Each student's comprehensive evaluation index B:

$$
\begin{aligned}
& B_{\mathrm{n}}=(0.25,0.5,0.25,0) ; B_{\mathrm{o}}=0.250 .50 .30 .25 ; \\
& B_{\mathrm{o}}=0,0.2,0.5,0.5 ; \mathrm{B}_{\mathrm{o}}=(0.25,0.5,0.3,0.25)
\end{aligned}
$$

for the convenient of comparison, we normalized the evaluation index

$$
B=\left(\frac{b_{1}}{\sum_{j=1}^{m} b_{j}} \frac{b_{2}}{\sum_{j=1}^{m} b_{j}} \quad L, \frac{b_{m}}{\sum_{j=1}^{m} b_{j}}\right)
$$

then we get four fuzzy comprehensive evaluation index

$$
\begin{aligned}
& B_{\mathrm{n}}^{\prime}=\left(\frac{0.25}{1}, \frac{0.5}{1}, \frac{0.25}{1}, \frac{0}{1}\right)=(0.250 .50 .250) \\
& \mathrm{B}_{\mathrm{o}}^{\prime}=\left(\frac{0.25}{1.3}, \frac{0.5}{1.3}, \frac{0.3}{1.3}, \frac{0.25}{1.3}\right)=(0.19,0.38,0.23,0.19) \\
& B_{\mathrm{o}}^{\prime}=\left(\frac{0}{1.2}, \frac{0.2}{1.2}, \frac{0.5}{1.2}, \frac{0.5}{1.2}\right)=(0,0.17,0.42,0.42) \\
& \mathrm{B}_{\mathrm{o}}^{\prime}=\left(\frac{0.25}{1.3}, \frac{0.5}{1.3}, \frac{0.3}{1.3}, \frac{0.25}{1.3}\right)=(0.19,0.38,0.23,0.19)
\end{aligned}
$$

thus the sequence of the four students who can pass the test is:

I , II and III, wherein student II and student IV tied for the second place.

Model II obtain the fuzzy comprehensive evaluation of each student: 


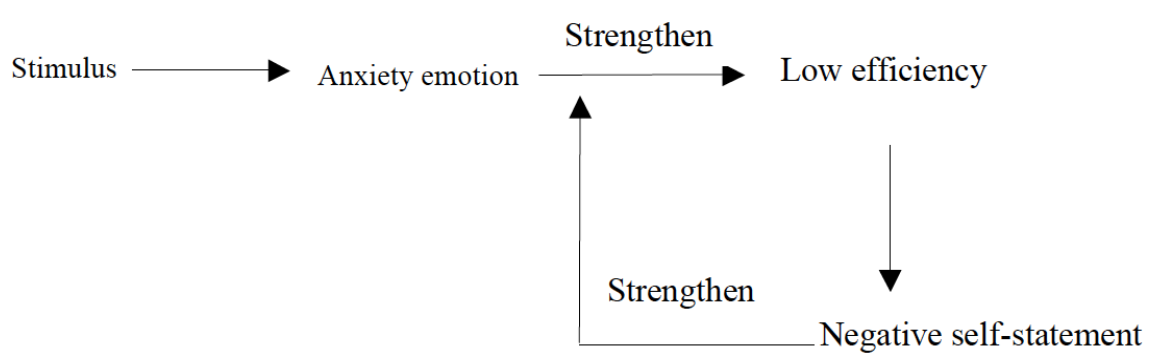

Fig. (2). The enhanced interaction of cognition and emotion.

$$
B_{1}=G \bullet R_{1}=(0.2,0.5,0.3) \bullet \mathrm{R}_{1}=\left(b_{1}, b_{2}, b_{3}, b_{4}\right)
$$

Based on the formula (2)

$$
\begin{aligned}
& b_{1}=(0.2 * 0.6)+(0.5 * 0.25)+(0.3 * 0.25)=0.32 \\
& b_{2}=0.45 ; b_{3}=0.23 ; b_{4}=0 \\
& B_{\mathrm{o}}=G \bullet \mathrm{R}_{\mathrm{o}}=\left(b_{1}, b_{2}, b_{3}, b_{4}\right)
\end{aligned}
$$

Similarly,

$$
\begin{aligned}
& b_{1}=0.125 ; b_{2}=0.375 ; b_{3}=0.375 ; b_{4}=0.125 \\
& B_{\circ}=G \bullet \mathrm{R}_{\circ}=\left(b_{1}, b_{2}, b_{3}, b_{4}\right) \\
& \text { in the same way, } \begin{array}{r}
b_{1}=0 ; b_{2}=0.05 ; b_{3}=0.5 ; b_{4}=0.45 \\
B=G \bullet \mathrm{R}=\left(b_{1}, b_{2}, b_{3}, b_{4}\right)
\end{array}
\end{aligned}
$$

empathy $b_{1}=0.175 ; b_{2}=0.425 ; b_{3}=0.325 ; b_{4}=0.075$

thus the four students' fuzzy comprehensive evaluation index are:

$$
\begin{aligned}
B_{1} & =(0.32,0.45,0.23,0) \\
B_{2} & =0.1250 .3750 .3750 .125\left(B_{3}=0,0.05,0.5,0.45\right. \text { ， } \\
\mathrm{B}_{4} & =(0.175,0.425,0.325,0.075)
\end{aligned}
$$

so the sequence of the four students who can pass the test is: I , IV, II , III.

\subsection{Forecast Results and Analyses}

Based on the stated work above, we can find that the sequence of the four students who can pass the test in Model I is I, II $(=\mathrm{IV})$, III, while in Model II, the sequence is I ,IV, II , III. Compare with the Model I, Model II tends to be more accurate.

In order to highlight the main influence factors, Model I simplify the operations.

Some $\mathrm{g}_{i}$ and $r_{i j}$ figures lost during the calculation process. Hence the loss of evaluation information leads to the distortion of the results. Model II however, combined the $\mathrm{g}_{i}$ and $r_{i j}$ and retain the whole information. Therefore Model II gets a better result.

\section{ENGLISH PROFICIENCY ANALYSIS OF COL- LEGE STUDENTS}

Through analyzing the pass rate of CET $4 / 6$ on the basis of fuzzy comprehensive evaluation model, we can see that assessment examination before the test owns the most impact on pass rate of CET $4 / 6$, in other words, we can measure the English proficiency of students by levels of examination before the test. We divided the results of assessment examination before the test into four layers: excellent, good, average, bad, of which the weight denote the English proficiency of the students. According to scientific research, the weight conform to the normal distribution. The proportion of each area that shaped by $X$ axis and weight are: excellent $5 \%$, good $34 \%$, average $46 \%$, bad $15 \%$. The reason for this is different purposes of college students.

According to the survey, the main purposes of English studying consist in meeting the requirement of the society, taking tests and individual interest. Through English study to find a good job takes a high proportion, which amounts to $69 \%$. 23\% people, however, forced to learn English only for various tests, which are lack of persistence and enthusiasm. The left $8 \%$ people choose to learn English on their will, it's just an individual interest, which means their study process bear with randomness and blindness.

There are many factors can exert an influence on English studying. The interplay between the learning mood and selfefficacy, see Fig. (2).

We can find that for the same foreign language learning, some students have a positive mood, but rather more students stay in low mood when studying. During the formation of learning difficulties, the inefficient learning strategy has been formed as a result of negative learning mood. We can see the excellent and bad students only take a small part of the proportion, and the good and average students become the mainstream. In addition, college students English proficiency are affected by their learning purpose as well as the CET 4/6. Underside we will further talk about the advantages and disadvantages of the CET $4 / 6$.

\section{ADVANTAGE AND DOSADVANTAGE OF THE CET 4/6}

As a national English examination, CET can analyze the practical English capability objectively and accurately. For most students, English test for college students do more good than harm, every language test is just a means of testing your proficiency, not end goal. The real purpose for English learning is to enhance our verbal communication skills, employment ability and international image.

The constraint effects of CET do have a good impact on English studying. "Shepherd type" self-study pattern makes many students even don't care about their Professional Courses, let alone the English study, thus to waste their 
golden age for English learning from 18 to 22 years old. And the loss of English language capability worsen the employment condition as the shortage of core competitiveness. While the pressure form CET can rapidly transformed into motivation for English studying, which is good for students with low self-control. Besides, life is sort of like an examination, we may face numerous tests as long as we live in the society and the CET is a must. It can improve our abilities of learning, thinking, communicating, persisting and coping with stress.

But the CET can not be endowed with other capabilities, and the dissimilation of the CET results not only represent the students' scores, but also an important index of teaching standards. Then unavoidable, the teaching staff begin to only concern about the scores and ignore the basic English ability training, which leads to "Deaf English" and "Exam English". So we should highly concern about this problem in English reform.

\section{CONCLUSION}

Through forecasting the pass rate of CET 4/6 by fuzzy theory and combined with the previous research, this paper finally get a accurate estimating model, which lays a theoretical and experimental foundation for estimating and forecasting the pass rate of CET 4/6. The level of assessment examination not only have a great impact on the pass rate, but also on students' English proficiency. Above all, it's a true reflection of students level.

By discussing we know that CET has both advantages and disadvantages for English learning. On one hand, it can arouse the enthusiasm and transform the pressure into moti- vation, which is good for low self-control students; on the other hand, the CET can not be endowed with other capabilities except level test, videlicet, the abnormal alienation and ignorance of English capacity training should be considered in English reform.

\section{CONFLICT OF INTEREST}

The authors confirm that this article content has no conflict of interest.

\section{ACKNOWLEDGEMENTS}

Declared none.

\section{REFERENCES}

[1] L. F. Bachman, and A. S. Palun, "Language Testing in Practice," Oxford: Oxford University Press, 1996.

[2] X. Li, "The Science and Art of Language Testing," Changsha: Hunan Education Publishing House, 1997.

[3] H. Yang, and C. Weir, "Validation Study of the National College English Test," Shanghai: Shanghai Education Press, 1998.

[4] Y. Liu, and W. Yang, "Result of analysis of oral English test," China Electric Power Education, vol. 20, pp. 189-191, 2011.

[5] D. Li, "A research on English learning method", Theory Research, vol. 20, pp. 278-279, 2013.

[6] X. Fang, "A Study on College English Teachers' Use of Motivational Strategies in Class," Shanghai: Shanghai International Studies University, 2012.

[7] L. Jin, "A preliminary research on the way to promote the teaching method of Business English", Journal of Nanjing Institute of Industry Technology, vol. 2, no. 3, pp. 65-67, 2003.

[8] H. Kang, "Research on the way to promote student listening proficiency", Journal of Qinghai Nationalities Institute, vol. 3, no. 30, pp. 128-130, 2004.

Received: June 10, 2015

Revised: July 29, 2015

Accepted: August 15, 2015

(C) Liu et al.; Licensee Bentham Open.

This is an open access article licensed under the terms of the (https:/creativecommons.org/licenses/by/4.0/legalcode), which permits unrestricted, noncommercial use, distribution and reproduction in any medium, provided the work is properly cited. 